\title{
Type III Pleuropulmonary Blastoma
}

National Cancer Institute

\section{Source}

National Cancer Institute. Type III Pleuropulmonary Blastoma. NCI Thesaurus. Code C45628.

A pleuropulmonary blastoma characterized by a solid pattern and sarcomatous features.

It usually follows an aggressive clinical course. 